\title{
MECANISMO DE RIFTEAMENTO DA PORÇÃO OCIDENTAL DA MARGEM NORTE BRASILEIRA, BACIA DO PARÁ-MARANHÃO
}

\author{
OSMAR ZANOTTO* e PETER SZATMARI*
}

\begin{abstract}
The Pará-Maranhão basin has been intensely studied during the past year by a special work group created in Petrobrás. Its tectonics evolution shows the key processes acting on the Equatorial Margin of Brazil of which it occupies part of its western portion. The basin is bordered to the south by a shallow offshore basement high, the Pará-Maranhão Platform, limited at the W by largely E-W trending and at the E by largely NW trending faults. Faults within the basin and bordering inner or external basement lighs (MAS-9, and 1-PAS-19) follow the orientation of faults along the basin margin of the respective (eastern and western) segments. Between the two portions, the NNE trending Gurupi high may mark the NE extremity of a major intracontinental fault; lesser faults trend NNW in the western and NNE in the eastern segment of the basin. The Mesozoic tectonic evolution of the area is proposed to have taken place in four stages. In Triassic-Jurassic time, contemporaneously with the intrusion of NNW trending basalt dikes along the Amapá margin to the west, the area was submitted to NNW-SSE compression and ENE-WSW extension characteristic of the break-up of Pangea. This compression is increased in early Cretaceous (Neocomian) time by the clockwise rotation of South America as the South Atlantic rift opened. During Alagoas (Aptian) time rifting along the Equatorial Margin reactivated NW-trending strike slipe and E-W trending reverse faults of this compressional phase as normal faults, within NE-trending major strike slipe faults of the compressional phase separate the $\mathrm{E}$ and the $\mathrm{W}$ portions of the basin. In Albian-Cenomanian time, right lateral movement between NW Africa and Brazil along the early Equatorial fracture zones reactivated the E-W faults as strike slip and the NW trending faults as normal faults, thus enhancing normal faulting and subsidence in the eastern relative to the western portion of the basin, from late Cretaceous time, thermal subsidence dominates.
\end{abstract}

generalidades A Bacia do Pará-Maranhão localiza-se na margem equatorial brasileira, limitada a NE pela cota batimétrica de $200 \mathrm{~m}$ (limite operacional atual), a SE pela Bacia de Barreirinhas, a NW pela bacia da foz do Amazonas e a SW pelo embasamento raso da Plataforma do Pará-Maranhão, cobrindo uma área de $25.000 \mathrm{~km}^{2}$ totalmente na parte submersa (Fig. 1).

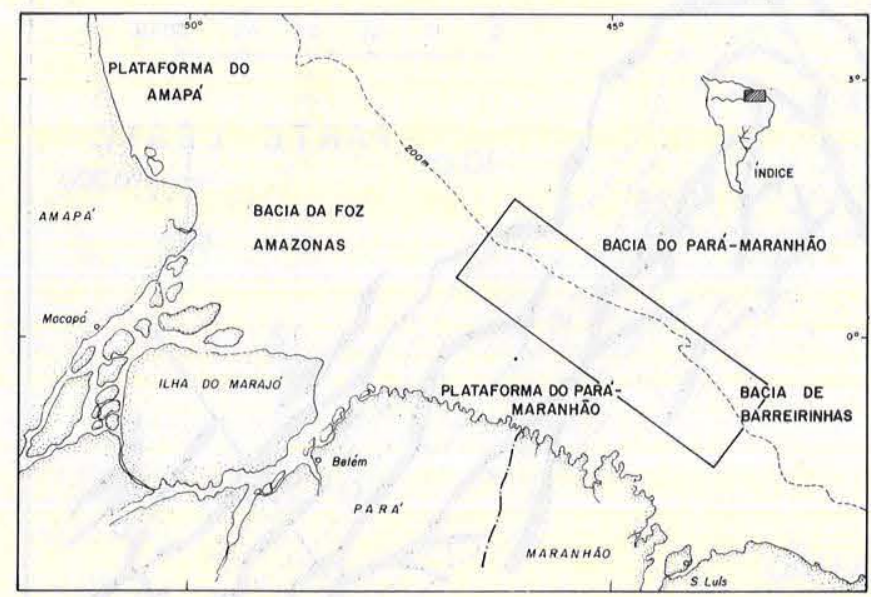

Figura 1 - Mapa de localização da área estudada

Os trabalhos de levantamento geofísico foram realizados entre 1967 e 1969, e consistem em aeromagnetometria, gravimetria e sísmica, sendo que os primeiros poços foram perfurados em 1978. Até o momento, existem 22 poços, sendo que um foi perfurado pela Hispanoil.

$O$ principal resultado alcançado em termos de descobertas de hidrocarbonetos foi a acumulação do 1-PAS-11. Os poços 1-MAS-5, 11, 12 e 17 apresentaram bons indícios de hidrocarbonetos, mas revelaram-se subcomerciais.

ESTRATIGRAFIA Os primeiros registros sedimentares desta bacia, até o momento amostrados, datam do Eocretáceo (Andar Alagoas Superior), zona palinológica conhecida como P-270, segundo Regali (1985) (Fig. 2).

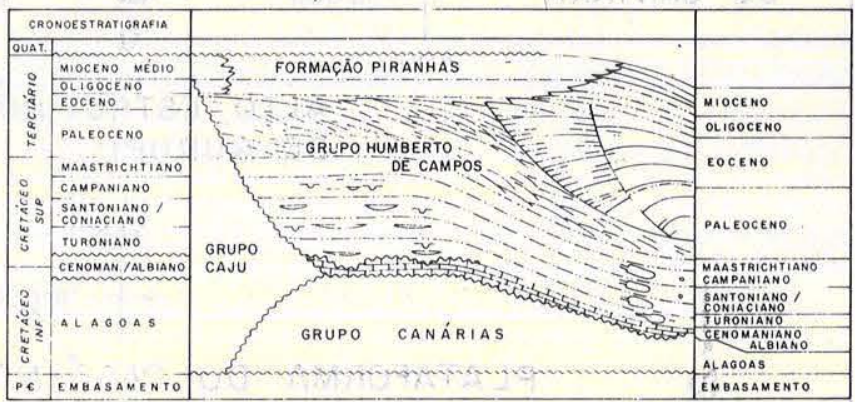

Figura 2 - Coluna estratigráfica. Fonte: Depex/Senort

A Formação da Bacia teve início durante o rifteamento . das placas Sul-Americana e Africana e é representada por uma sedimentação intensa de clásticos flúvio-deltaico-baci-

* Petróleo Brasileiro S.A. (Petrobrás), Centro de Pesquisas e Desenvolvimento Leopoldo A. Miguez de Mello (Cenpes), Divisã́o de Exploração. Cidade Universitária, Quadra 7, Ilha do Fundão, CEP 21910, Rio de Janeiro, RJ, Brasil 
nais-lacustres. A parte bacinal constitui-se por folhelhos sílticos calcíferos e arenitos finos a muito finos, síltico-argilosos, depositados em áreas distais de frente deltaica, prodel ta e talude lacustre. Na parte mais proximal o sistema flúvio-deltaico caracteriza-se por arenitos finos a grossos, argilosos com níveis de folhelhos sílticos, micáceos, carbonosos, evidenciando deposição subaérea ou de águas rasas.

Utilizando-se a nomenclatura estratigráfica da Bacia de Barreirinhas proposta por Figueiredo et al. (1982), este pacote pertence ao Grupo Canárias, sendo a fácies mais proximal representante da Formação Barro Duro e a mais distal da Formação Arpoador. Este pacote é correlacionado ainda aos sedimentos Cassiporé do gráben homônimo.

Uma fase erosiva instala-se na costa norte brasileira durante o final do Andar Alagoas e início do Albiano, que nesta área foi responsável pela erosão de centenas de metros de sedimentos do Andar Alagoas.

Sobre o pacote Alagoas assentam discordantemente os sedimentos do Albiano, representados por um sistema carbonático de plataforma rasa, talude e bacia, com calcarenitos, cacilutitos, folhelhos carbonosos e calcíferos, amostrados somente na parte leste da bacia (1-MAS-12 e 11). Os sedimentos são equivalentes aos do Grupo Caju da Bacia de Barreirinhas, situada a sudeste, onde esta seção é.bem conhecida e atinge milhares de metros de espessura. Este pacote não está presente em grande parte da Bacia do ParáMaranhão, até o momento perfurada, e provavelmente esteja presente apenas na parte leste e norte da bacia, onde distalmente possa ser concordante com os sedimentos do Andar Alagoas.

Durante o Cenomaniano, nova fase erosional denuda parte do pacote Albiano, principalmente nas áreas mais proximais, segundo análises paleontológicas.

No período entre Turoniano e Paleoceno-Eoceno Inferior depositaram-se sedimentos clásticos num sistema de talude marinho-bacial, constituídos de folhelhos e margas, siltitos, calcíferos micáceos e arenitos finos e muito finos argilosos calcíferos de origem turbidítica. Esta seção sedimentar é correlacionada à Formação Limoeiro (fácies basal) da foz do Amazonas (Cassiporé) e ao Grupo Humberto de Campos da Bacia de Barreirinhas.

A partir do Paleoceno-Eoceno Inferior implanta-se um sistema de plataforma e talude marinhos, permitindo a formação de uma espessa unidade carbonática e com calcarenitos finos a médios, bioclásticos, gradando distalmente para calcilutitos micríticos argilosos. Esta fase de grande atividade orgânica aliada à subsidência térmica atenua-se sensivelmente a partir do Mioceno Superior.

ARCABOUÇO TECTÔNICO As principais feições geotectônicas estão apresentadas na figura 3:

- Alto do embasamento a SW da bacia, chamado de Plataforma do Pará-Maranhão.

- Alto do 1-MAS-9, alongado e estreito de direção E-W situado a norte da Plataforma do Pará-Maranhão.

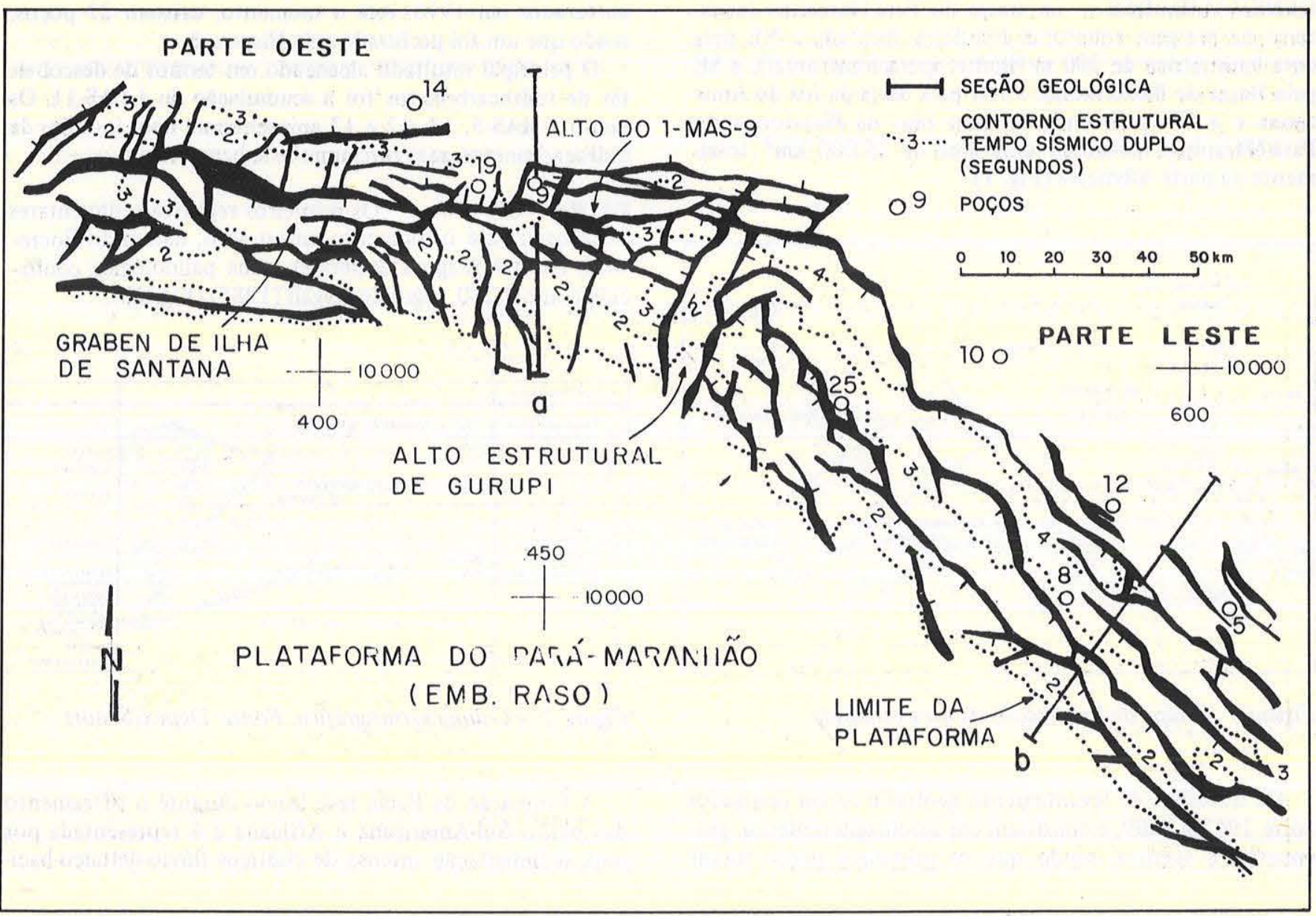

Figura 3 - Mapa estrutural do embasamento, mostrando as principais feições geotectônicas. Adaptado do Grupo de Trabalho da Bacia do Pará-Maranhão (1985) 
- Gráben de Ilha de Santana, no geral é um meio-gráben de aproximadamente $25 \mathrm{~km}$ de largura encaixado entre a Plataforma do Pará-Maranhão e o Alto do 1-MAS-9.

- Alto estrutural de Gurupi, de direção NE, situado no ponto de mudança de direção da Bacia de SE-NW para E-W, coincidente com o prolongamento do Alto de Gurupi mapeado na parte emersa.

- Áreas mais profundas na parte norte do Alto do 1-MAS-9 e na parte leste da bacia, com falhamentos escalonados.

A Bacia do Pará-Maranhão, conhecida e mapeada sismicamente, pode ser dividida segundo as feições geotectônicas e seu estilo tectono-sedimentar em duas porções (Figs. 3 e 4).

- Parte leste, onde predominam as falhas de direção N10W e N50W com abatimento de blocos num sistema de falhas normais, principalmente antitéticas, com grandes rejeitos, escalonados, permitindo a acomodação de um pacote sedimentar que atinge mais de $7 \mathrm{~km}$ de espessura nas áreas mais distais. A bacia nesta parte tem uma direção geral SE-NW (Figs. 3, 4B, 5C, 5D).

- Parte oeste, onde predominam os segmentos de falhas com direção $\mathrm{E}-\mathrm{W}$ e $\mathrm{N} 30 \mathrm{E}$, este último mais importante na parte central da bacia. Consiste basicamente em um meio-gráben encaixado entre o alto do embasamento da Plataforma do Pará-Maranhão e o Alto do 1-MAS-9, que também como o meio-gráben apresenta direção principal E-W. O pacote sedimentar no meio-gráben é menos espesso e consiste em sedimentos de idade Alagoas. A falta de poços mais distais do Alto do 1-MAS-9 impede uma melhor avaliação dos atributos sedimentares, e também os registros sísmicos perdem em resolução devido à grande profundidade que se encontra a seção rifte (Figs. 3, 4A, 5A e 5B).

$\mathrm{O}$ sistema de falhas na Bacia do Pará-Maranhão apresenta quatro direções principais, segundo sua orientação:

- Falhas de direção N30E consistindo em segmentos rela- tivamente curtos e mais importantes na porção oeste e central da bacia, onde ocorre a deflexão dos segmentos E-W para NW-SE da bacia (Fig. 5A).

- Falhas de direção E-W com segmentos longos e bem expressivos na porção oeste da bacia, onde assumem grande importância (Fig. 5B).

- Falhas de direção N10W com segmentos curtos e boa distribuição na parte leste da bacia e pouco expressivos na porção oeste (Fig. 5C).

- Falhas de direção N50W com melhor distribuição na parte leste da bacia, e apresentam segmentos relativamente mais longos (Fig. 5D).

Os segmentos de falhas com orientação N30E são truncados principalmente pelo sistema de direção $\mathrm{E}-\mathrm{W}$.

O conjunto desses sistemas de falhas permitiu a criação de uma série de horsts, grábens e meio-grábens, que refletem basicamente o padrão das direções desses segmentos, com abatimento de blocos num sistema sintético na parte oeste e principalmente antitético na parte leste da bacia (Fig. 3).

A linha de limite da bacia contra a Plataforma do Pará-Maranhão é recortada por falhas, criando meio-grábens encaixados e a posterior erosão deste pacote sedimentar fornece um traçado curvo em várias situações. Onde ocorrem os baixos, a Bacia penetra mais na plataforma do ParáMaranhão (embasamento raso) e os altos permitem que a plataforma avance dentro da bacia compartimentando-a, como ocorre no prolongamento do lineamento de Gurupi (Alto de Gurupi), que divide a bacia em parte leste e oeste no ponto de inflexão das direções E-W e SE-NW (Fig. 3). No sistema de rifte, o bloco (Alto do 1-MAS-9) não sofreu praticamente abatimento, resultando num alto alongado e estreito de direção E-W, situado a norte da Plataforma do Pará-Maranhão separando a Bacia Marginal propriamente dita do gráben de Ilha de Santana encaixado ao sul (Fig. 3).

Para o sistema com um todo, o comportamento é
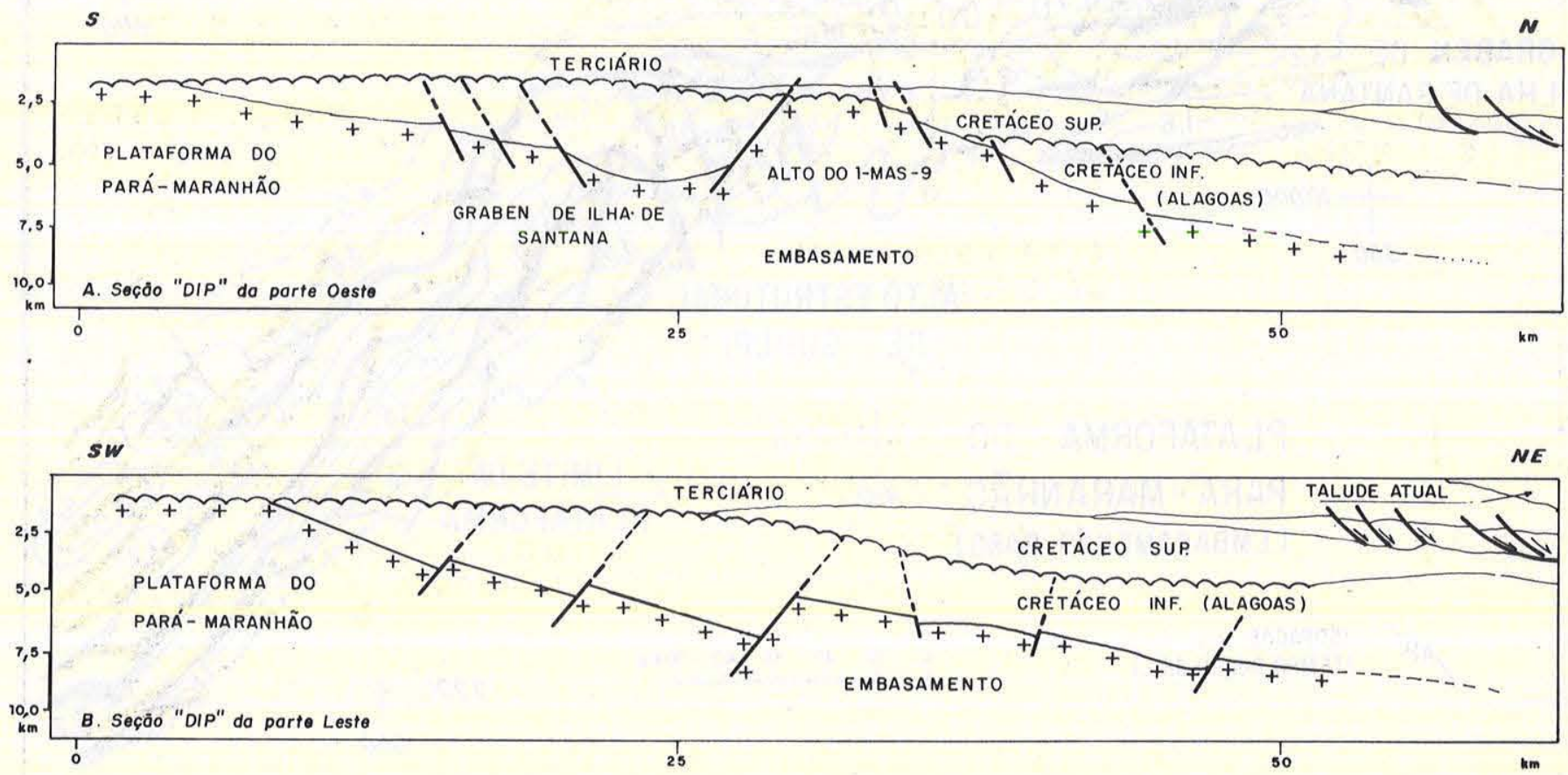

Figura 4 - Seções geológicas esquemáticas representativas da parte oeste e leste da Bacia do Pará-Maranhão 

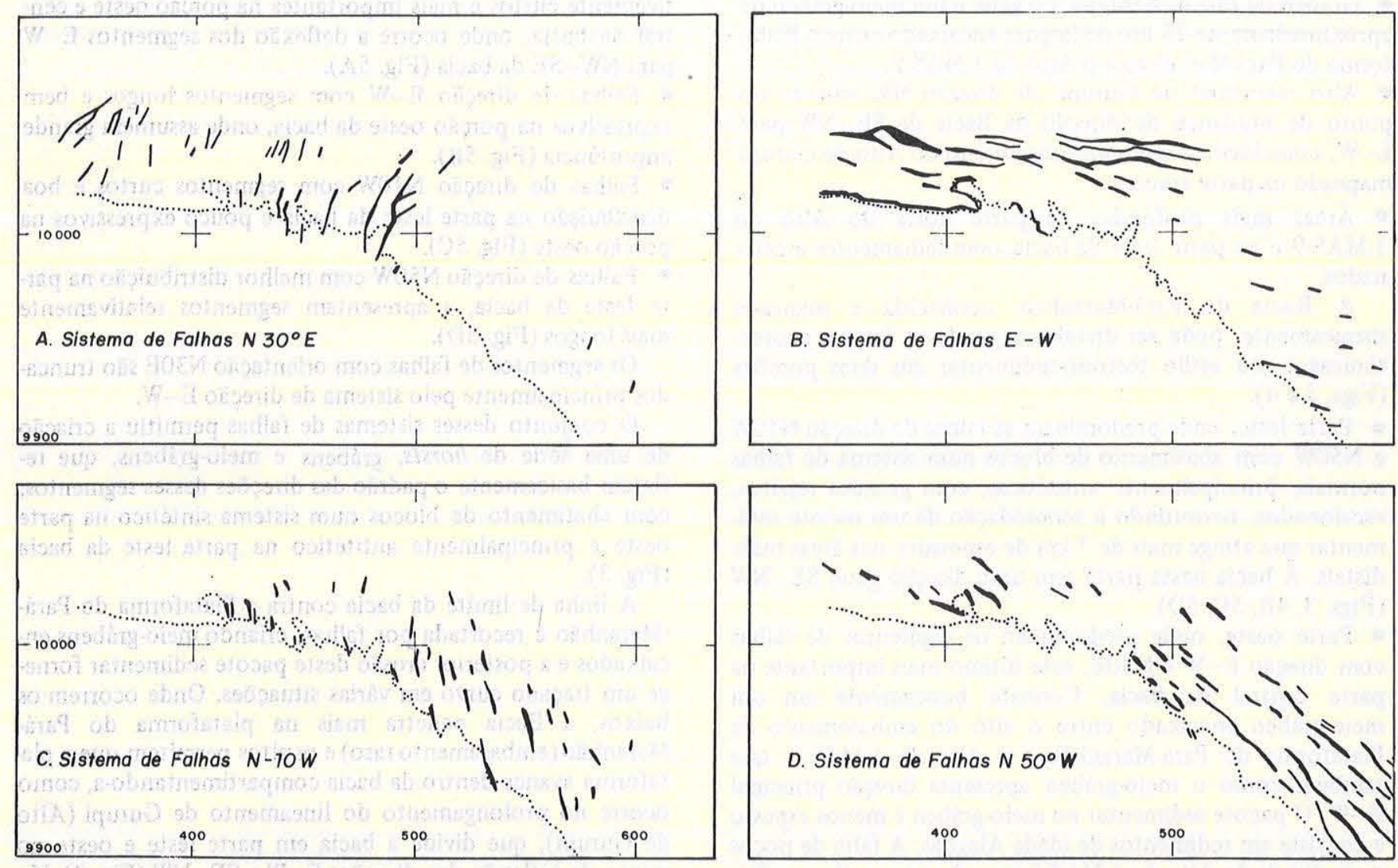

Figura 5 - Sistemas de falhas da Bacia do Pará-Maranhão

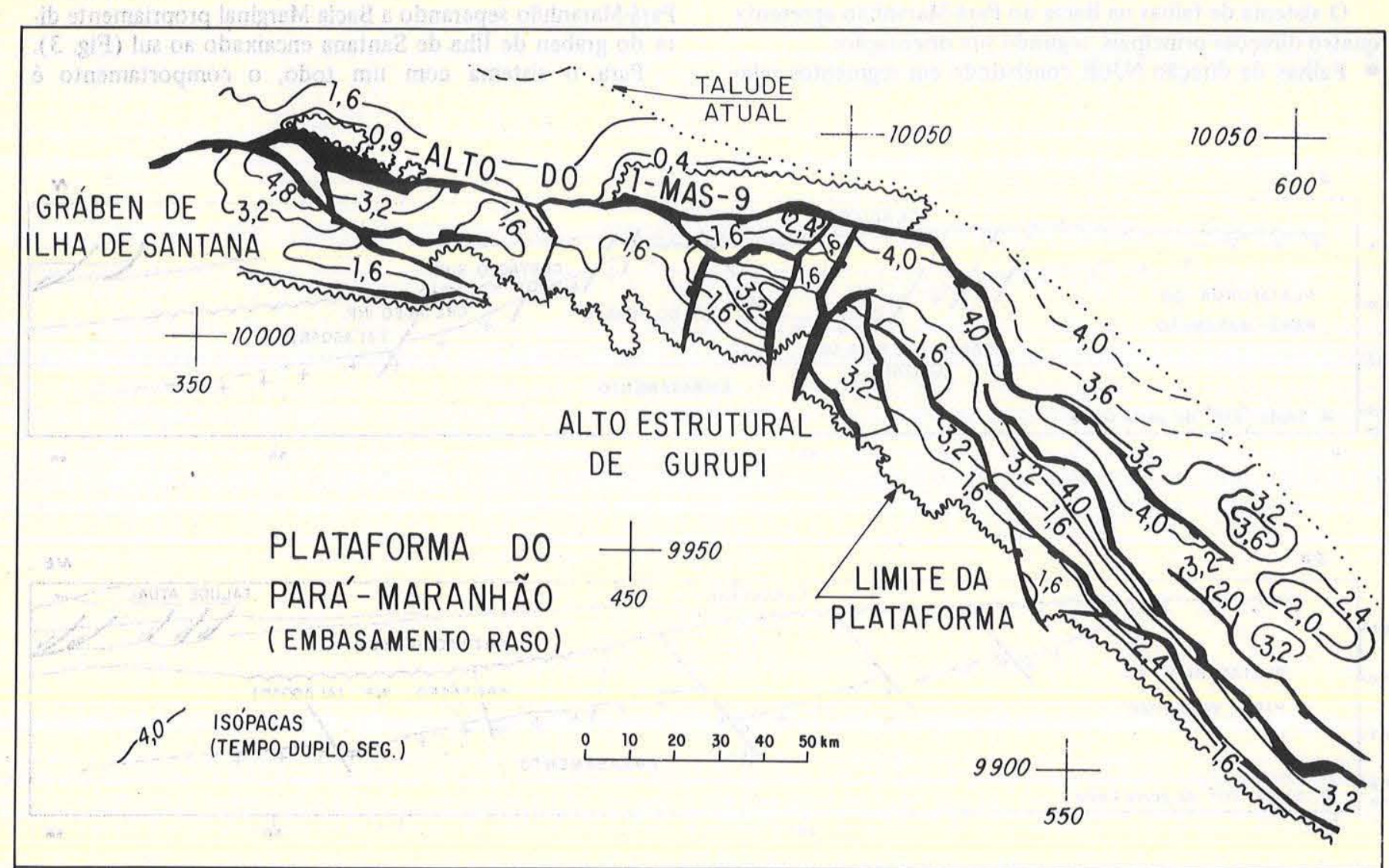


nitidamente de falhamentos normais na fase de rifteamento, sendo que com o prosseguimento da migração das placas continentais assumem características distintas.

Nesta migração, os segmentos de orientação principal E-W tornam-se basicamente transcorrentes, levemente divergentes com pouco abatimento dos blocos. Os segmentos SE-NW agem extensionalmente, acentuando ainda mais o abatimento dos blocos nessas áreas. Isso resulta numa bacia mais profunda na parte leste e menos profunda na oeste, para zonas consideradas a uma mesma distância do limite da Plataforma do Pará-Maranhão (Fig. 3).

EVOLUÇÃO GEOTECTÔNICA O desenvolvimento geotectônico da área da Bacia do Pará-Maranhão compreende as seguintes fases:

- Jurássico - A área encontrava-se contígua com a parte ocidental da África com as grandes bacias paleozóicas do Parnaíba e do Amazonas adentrando parcialmente no continente africano (Fig. 8A).

- Cretáceo Inferior (Neocomiano) - Esforços compressionais NNW-SSE criam amplos e suaves altos ENE-WSW, dos quais são registros a Plataforma de Pará-Maranhão e mais ao sul o Arco Guama-Ferrer-Urbano Santos descrito por Resende \&Pamplona (1970). Falhas normais de alívio paralelas ao esforço compressional ocorrem principalmente na porção oeste e falhamentos reversos, mas de difícil comprovação, perpendiculares ao esforço compressional. Falhas transcorrentes sinistrais, como a de Gurupi, serviram de alívio dos esforços oriundos de NNW e SSE. A causa dos esforços compressionais tem sua origem na abertura do
Atlântico Sul pela rotação horária da Placa Sul-Americana em relação à Africana (Figs. 5 e 8B).

- Cretáceo Inferior (Andar Alagoas) - Esforços extensionais de direção NNE-SSW, atribuídos ao prosseguimento da abertura do Atlântico Sul, propagam o rifte de leste para oeste na margem equatorial brasileira. Nesta fase ocorrem os primeiros registros sedimentares da bacia com rápida deposição de clásticos terrígenos, preenchendo os grábens e semi-grábens estreitos e alongados com orientações principais E-W e SE-NW, sendo que a mudança de direção é condicionada pelo lineamentọ de Gurupi de direção NE ativo durante esta fase (Figs. 5, 6 e 8C).

- Albiano Superior a Cenomaniano - Prossegue a separação dos dois continentes, com movimento transcorrente levemente extensional $\mathrm{E}-\mathrm{W}$. Os riftes de direção SE-NW continuam com abatimento num sistema de bacia pullapart, desenvolvendo uma deposição de carbonatos de plataforma, talude e bacia. As áreas de riftes E-W apresentam caráter transcorrente levemente extensional com menor abatimento de blocos, resultando em altos do embasamento como os do 1-MAS-9 e 1-PAS-19, que ficam expostos à erosão de parte do pacote Alagoas, principalmente nas áreas mais proximais. Nesta fase instala-se a seqüência carbonática, bem conhecida no segmento $\mathrm{SE}-\mathrm{NW}$ da bacia (1:MAS-11 e 12) e principalmente na Bacia de Barreirinhas (Figs. 5, 7 e 8D).

- Cretáceo Superior ao Terciário - No decorrer deste período o principal componente, além da separação dos continentes sul-americano e africano, é o basculamento térmico

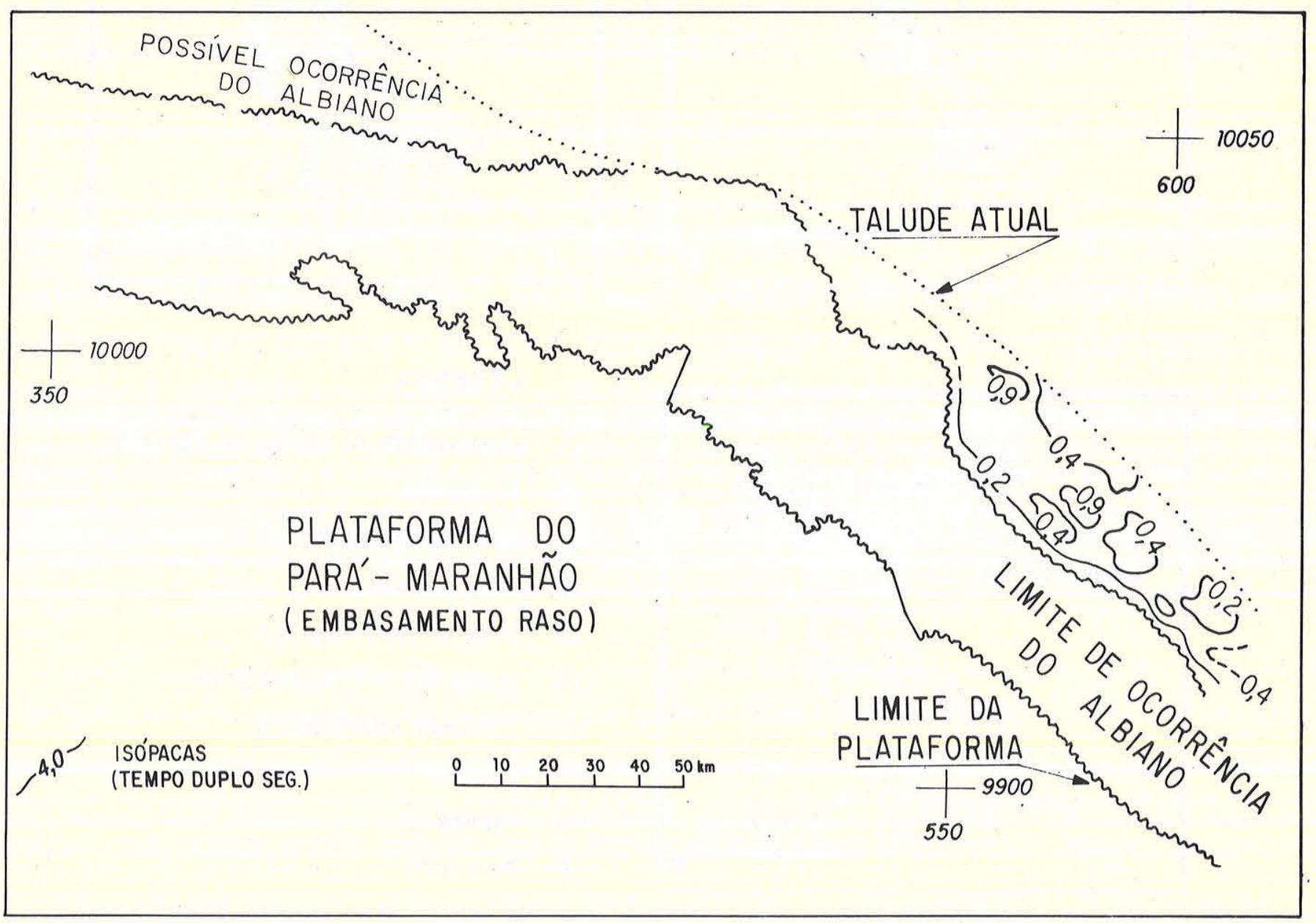

Figura 7 - Mapa de isópacas do Andar Albiano, segundo o Grupo de Trabalho da Bacia do Pará-Maranhão (1985) 

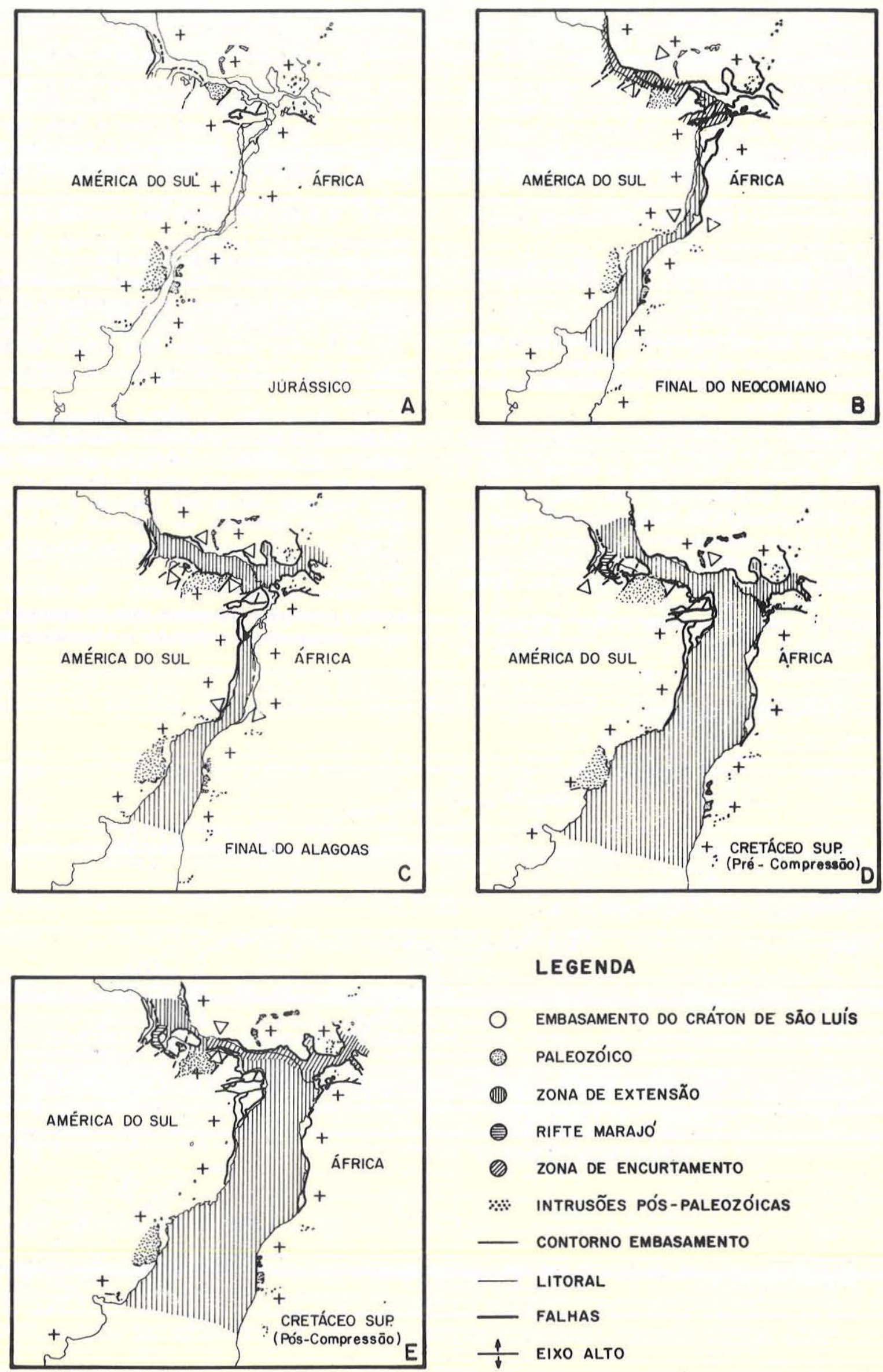

\section{LEGENDA}

O Embasamento do CRÁton dE sÃo Luís

(2) PALEOZÓICO

III ZONA DE EXTENSÃo

() RIFTE MARAJO'

- zONA DE ENCURTAMENTO

… INTRUSÕES PÓS-PALEOZÓICAS

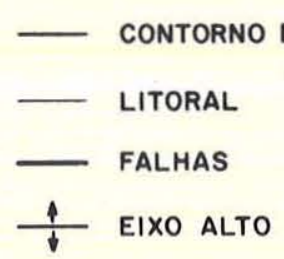

Figura 8 - Esquemas evolutivos da separação dos continentes sul-americano e africano, segundo Rabinowitz \& La'Brecque (1979), modificado por Szatmari et al. (1985a) 
realçando ainda mais o Alto de Gurupi (Fig. 8E). Os registros sedimentares são uma seção clástica na parte basal com características representativas de um sistema de talude marinho-bacial, que a partir do Paleoceno-Eoceno Inferior dá lugar a um sistema de plataforma carbonática média a externa e talude marinho representados pelo Grupo Humberto de Campos. Esta fase com tendência negativa diminui sensivelmente a partir do Mioceno Inferior.

\section{REFERÊNCIAS BIBLIOGRÁGICAS}

FIGUEIREDO, A.M.F.; TEIXEIRA, L.; AMORIM, J.; CARMINATTI, M. - 1982 - Projeto Barreirinhas, reavaliação da bacia cretácea. Ärea terrestre e maritima. Petrobrás/Depex (relatório interno).

GRUPO DE TRABALHO DA BACIA DO PARĀ-MARANHÃO 1985 - Análise da Bacia do Pará-Maranhão. Petrobrás/Depex (relatório interno).

MIURA, K. \& BARBOSA, J.C. - 1972 - Geologia da plataforma continental do Maranhão, Piauí, Ceará e Rio Grande do Norte: In: CONGR. BRAS. GEOL., 26, Belém, 1972. Anais..., Belém, SBG, v. 2, p. 57-66.

RABINOWITZ, P.D. \& LA'BRECQUE, J. - 1979 - The mesozoic south atlantic ocean and evolution of its continental margins. $J$. Geophys. Res., 84:5973-6002.

RESENDE, W.M. \& PAMPLONA, H.R.P. - 1970 - Estudo do desenvolvimento do arco Ferrer-Urbano Santos. Bol. Téc. Petrobrás, Rio de Janeiro, 13:5-14.
REGALLI, M.S.P. - 1985 - Síntese palinoestratigráfica do Cretáceo nas margens equatorial e leste do Brasil. In: CONGR. BRAS. PALEONT., 9, Fortaleza, 1985 (no prelo).

SZATMARI, P.; FRANÇOLIN, J.; ZANOTTO, O.; WOLFF, S. 1985a - Evolução tectônica da margem equatorial brasileira Rev. Bras. Geoc., 17(1):180-188.

SZATMARI, P.; MILANI, E.J.; LANA.; M.C.; CONCEIÇÃO, J.C.J.; LOBO, A.P. - 1985b - How South Atlantic rifting affects brazilian oil researchs distribution. Oil \& Gas $J$. 83(2):107-113.

MANUSCRITO 392

Recebido em 01 de agosto de 1986 Revisão aceita em 06 de fevereiro de 1987

"Embora o passo fundamental da nova universidade comprometida com a revolução das idéias passe por uma mudança no comportamento dos segmentos universitários, isto deverá ocorrer dentro de um processo dialético, onde o comportamento influi na construção da nova universidade e uma nova universidade surge induzindo a mudança no comportamento". 